\title{
Comparative study between unengaged and engaged fetal head in primigravida at term or in labour
}

\author{
Deep Mahendra Bhadra*, Pundalik Krishna Sonawane
}

Department of Obstetrics and Gynecology, K. J. Somaiya Medical college, Mumbai, Maharashtra, India

Received: 22 August 2018

Accepted: 27 September 2018

\section{*Correspondence:}

Dr. Deep Mahendra Bhadra,

E-mail: deepbhadra67@gmail.com

Copyright: (C) the author(s), publisher and licensee Medip Academy. This is an open-access article distributed under the terms of the Creative Commons Attribution Non-Commercial License, which permits unrestricted non-commercial use, distribution, and reproduction in any medium, provided the original work is properly cited.

\begin{abstract}
Background: The aim of the study is to compare and evaluate between unengaged (UE) and engaged (E) groups at term or in labour, incidence of unengaged and engaged heads, need for medical or surgical intervention, progress of labour and feto-maternal outcome.

Methods: It is a prospective comparative study carried at tertiary care hospital for a period of 18mths from May16November17. Out of 377 patients, 100 patients were selected in each group with unengaged (group A) and engaged (group B) heads. Patients consent, and ethical approval was taken. History, examination and investigation was done at each visit. Incidence of unengaged heads at term or in labour, duration of each phase of labour and its partographic analysis, need for medical or surgical intervention, mode of delivery and fetomaternal outcome was calculated.

Results: Incidence of unengaged heads at term is $61 \%$. $17 \%$ patients in unengaged group as compared to $10 \%$ required induction of labour while $73(73 \%)$ patients in unengaged group required augmentation with oxytocin as compared to $36(36 \%)$ patients in engaged group. Duration of labour in each phase was more in unengaged group. Incidence of lower segment caesarean section (LSCS) was $37 \%$ in unengaged group as compared to $23 \%$ in engaged group. Fetomaternal morbidity which was higher in unengaged was documented.

Conclusions: Although with unengaged head being a significant risk factor for LSCS, with watchful expectancy and careful intervention, most patients will deliver vaginally with minimal fetomaternal morbidity.
\end{abstract}

Keywords: Engaged, Lower segment caesarean section, Unengaged

\section{INTRODUCTION}

Labour is an important event with unique experience exclusively in a woman's life. ${ }^{1}$ It is characterized by uterine contraction that affect the dilatation of cervix and force the foetus through the birth canal. Engagement of head has been defined as passage of widest diameter (biparietal diameter) of foetal skull through the plane of the pelvic inlet. It is generally accepted that high foetal station in primigravidas in labour near term may indicate a threat to the normal progress of labour because of foetopelvic disproportion or obstruction of the foetal passage by tumor or the placenta. ${ }^{2}$ Although the engagement of the foetal head is regarded as a phenomenon of labour, it is usually delayed in nulliparas and commonly occurs during the last few weeks of pregnancy. ${ }^{3}$ When engagement occurs, it is confirmatory evidence that pelvic inlet is adequate for that foetal head. However, a significant number of primigravidae still do present with unengaged head at the onset of labour. ${ }^{4}$

Friedman and Sachtleben demonstrated that higher station at the onset of labour were associated with an increase in the duration of labour and in the incidence of dysfunctional labour patterns. ${ }^{5}$ In study done by Thenmozhi and Iyer, engagement of head at the onset of 
labour was found in $15.34 \%$ cases. $^{6}$ They have observed a proportionate prolongation in the latent phase of labour in patients with high station. In prolonged labour, mother is exposed to high risk of infections, ketosis and obstructed labour while foetus has the risk of low APGAR at birth, asphyxia and meconium aspiration syndrome. ${ }^{7}$

Therefore, an unengaged head in a nulliparous woman in active labour can be an indication for caesarean delivery. ${ }^{8}$ However some studies have shown that a substantial proportion of them deliver vaginally with no increase in maternal or foetal morbidity and mortality. ${ }^{9}$

Partogram is a graphic record of progress of labour and maternal and fetal condition during labour in a single sheet of paper which is useful in detecting the labour that is not progressing normally at an early stage and helpful in its management. ${ }^{10}$

The purpose of this study was thus to find out the incidence of unengaged heads at term or at onset of labour, make partographic analysis of progress of labour in primigravida females with unengaged versus engaged head, to determine role of active medical and surgical interventions and to determine foeto-maternal morbidity.

\section{METHODS}

It is a prospective comparative study conducted at a tertiary care hospital Mumbai from May 2016 and November 2017. 377 primigravidas attended our OPD with gestational age of equal to or $>37$ completed weeks and $<42$ completed weeks either for routine ANC checkup or in labour. According to 'OPENEPI' software at $95 \%$ confidence interval and $80 \%$ power of study for sample size estimation, minimum cases required in Group ' $A$ ' is 63 and Group ' $B$ ' is 63. But since my study duration was for 18 months, I had taken 100 cases in each group.

Detailed history was taken regarding parity, duration of pregnancy and history of labour pains if present, whenever they visited us in our OPD. Gestational age was calculated according to her LMP (last menstrual period). In those patients who were not sure of their dates, gestational age was calculated based on their earliest ultrasound.

General physical examination (i.e. height and weight) and detailed obstetric examination which included abdominal examination for fundal height, lie, presentation, engagement, amount of liquor, estimated foetal weight, palpable uterine contractions and foetal heart rate. Pelvic examination was done which included following points: prominence of sacral promontory, interspinous diameter, sacral hollow and subpubic arch to rule out contracted pelvis. Ultrasound was done to confirm above findings.

Those patients who presented with labour pains were enrolled according to the inclusion and exclusion criteria and those not in labour but having fulfilled inclusion and exclusion criteria (except labour factors) were followed up with routine ANC visits till 40 weeks on OPD basis or till they go in labour whichever is earlier. Ethical committee approval was taken.

\section{Inclusion criteria}

- Primigravida

- Term pregnancy (37-42) weeks

- Expected foetal birth weight of 2.5-4.0 kg on USG at term

- $\quad$ Singleton live pregnancy

- Cephalic presentation

- Cervical dilatation of $=/<3 \mathrm{cms}$

- Reactive CTG at term or at onset of labour.

\section{Exclusion criteria}

- Contracted pelvis

- Previous uterine surgery

- Pregnancy complications like antepartum haemorrhage, pregnancy induced hypertension, gestational diabetes mellitus, IUGR.

- Previous abortion.

These patients were divided in 2 groups with group ' $A$ ' consisted of 230 unengaged heads and group ' $\mathrm{B}$ ' consisted of 147 engaged foetal head in primigravida at term or in labour.

Engagement was defined as follows: the amount of foetal head felt suprapubically in finger breadth. It is estimated by number of fifths of head above pelvic brim (CRICHTONS METHOD).

- When 5/5: floating above the brim

- When 4/5: on the brim

- When 3/5: not engaged

- When 2/5: just engaged

- When 1/5: engaged

- When 0/5: deeply engaged

So unengaged head will be $3 / 5$ and above and engaged head will be $2 / 5$ and below.

Out of total 230 patients in Group A, 33 patients were lost to follow up. 63 patients were excluded as they did not fit into our inclusion and exclusion criteria as some patients developed medical complications like pregnancy induced hypertension, some came in active labour, some had non-reassuring CTG at onset of labour, some patients had contracted pelvis. Of the remaining 134 patients, first 100 patients coming in labour or at $40 \mathrm{wks}$ were included in present study.

Similarly, out of 147 patients in Group B, 17 patients were lost to follow up, 15 patients were excluded due to reasons as unengaged group. Of the remaining 115 
patients, first 100 patients who came in labour or at 40wks were included in present study.

All the patients from both the groups who came at the onset of labour or at 40 weeks whichever was earlier, were included in present study after detailed history, clinical examination and investigation. Appropriate consent was taken of all the eligible patients who were included in present study.

At onset of labour or at 40 weeks in all eligible patients from both the groups, pelvic examination was done for pelvic adequacy and BISHOPS score was calculated in those patients not in labour requiring induction of labour at 40wks using intracervical prostaglandin $\mathrm{PGE}^{2}$ gel.

Onset of labour was considered from time of onset of pain in lower abdomen or history of leaking per vaginum whichever is first. Those patients who were not in labour were monitored on OPD basis till 40 weeks. Those patients who were not in labour till 40 weeks and <42 weeks were induced with $\mathrm{PGE}_{2}$ gel after assessing pelvis, BISHOPS score and NST. In patients with spontaneous onset of labour, pelvic adequacy and CTG was done. Induced patients and the patients with reactive CTG at onset of labour were observed for duration of latent phase, duration of active phase and duration of second stage. Patients with inadequate uterine contractions were augmented with oxytocin.

The course of labour was recorded on partograph. Following outcomes were measured like; percentage of patients with unengaged head at term getting engaged at onset of labour or at 40 weeks, need for medical intervention like intracervical prostaglandins for induction of labour, need of oxytocin for augmentation of labour, progress of labour with total duration of labour including duration of latent phase, duration of active phase, rate of cervical dilatation in active phase, duration of second stage, intrapartal foetal distress, mode of delivery whether spontaneous vaginal delivery, assisted vaginal delivery or LSCS and the indication of LSCS, postpartal maternal outcome and neonatal outcome like APGAR score at 1 st and $5^{\text {th }}$ minute and NICU stay.

Above data was entered in proforma and analysed by SPSS version.

\section{RESULTS}

In present study of the total 377 patients seen in our OPD, incidence of unengaged heads at term is $230(61 \%)$. In unengaged group, mean gestational age at onset of labour is 39.12 weeks as compared to 38.21 weeks in engaged group. In unengaged group presenting at onset of labour or at 40 weeks, $17(17 \%)$ patients were at 5/5, $23(23 \%)$ were at $4 / 5,31(31 \%)$ were at $3 / 5,28(28 \%)$ were at $2 / 5$ and $1(1 \%)$ at $1 / 5.17(17 \%)$ patients in unengaged group as compared to $10(10 \%)$ patients in engaged group went till 40 weeks of gestation and required induction of labour while $73(73 \%)$ patients in unengaged group as compared to $36(36 \%)$ patients in engaged group required augmentation of labour.

Table 1: Comparison of mean duration of labour in each phase between unengaged and engaged groups.

\begin{tabular}{|llll|}
\hline $\begin{array}{l}\text { Mean duration of } \\
\text { each phase (hours) }\end{array}$ & Unengaged & $\begin{array}{l}\text { Engaged } \\
\text { Latent phase }\end{array}$ & $\begin{array}{l}\text { P } \\
\text { value }\end{array}$ \\
\hline Active phase & 5.48 & 8.41 & $<0.01$ \\
\hline $\begin{array}{l}\text { Rate of dilatation } \\
\text { (cm/hour) }\end{array}$ & 1.14 & 1.53 & $<0.01$ \\
\hline $1^{\text {st }}$ stage & 14.21 & 12.5 & $<0.01$ \\
\hline $2^{\text {nd }}$ stage (mins) & 34.38 & 29.44 & 0.12 \\
\hline
\end{tabular}

In patients presenting in spontaneous onset of labour, between 37-38 weeks, $6(7.22 \%)$ patients were from unengaged group and $39(43.33 \%)$ patients from engaged group, between $38-39$ weeks, 35 (42.16\%) patients were from unengaged group and $43(47.77 \%)$ from engaged group, between $39-40$ weeks, $38(45.78 \%)$ patients were from unengaged group and $5(5.55 \%)$ from engaged group and $>/=40$ weeks, $4(4.81 \%)$ patients were from unengaged group and 3 (3.33\%) from engaged group and the difference was statistically significant. Mean duration of labour in latent phase in unengaged group is 10.40 hours whereas in engaged group it is 8.51 hours, mean duration of labour in active phase is $5.48 \mathrm{hrs}$ in unengaged group and 4.13 hours in engaged group, mean duration of 1st stage is 14.21 hours in unengaged group as compared to 12.5 hours in engaged group, mean duration of second stage of labour is 34.38 mins in unengaged group as compared to 29.44 minutes in engaged group, mean rate of cervical dilatation in unengaged group is 1.14 hours as compared to 1.53 hours in engaged group,

Table 2: Comparison of outcome in unengaged and engaged foetal heads in primigravida at term.

\begin{tabular}{|c|c|c|c|}
\hline & \multicolumn{2}{|l|}{ Group } & \multirow{2}{*}{ P value } \\
\hline & Unengaged & Engaged & \\
\hline $\begin{array}{l}\text { Spontaneous } \\
\text { vaginal }\end{array}$ & $53(53 \%)$ & $70(70 \%)$ & \multirow{3}{*}{0.046} \\
\hline Instrumental & $10(10 \%)$ & $7(7 \%)$ & \\
\hline LSCS & $37(37 \%)$ & $23(23 \%)$ & \\
\hline
\end{tabular}

Out of 100 patients in unnegaged group, 53 (53\%) patients delivered by spontaneous vaginal delivery, 10 (10\%) delivered by instrumental delivery and $37(37 \%)$ delivered by LSCS as compared to $70(70 \%), 7(7 \%)$ and $23(23 \%)$ respectively in engaged group.

In patients going for LSCS, 18 (48.64\%) in unengaged group as compared to 9 (39.13\%) in engaged group had no progress of labour, $14(37.83 \%)$ in unengaged group as compared to $12(52.17 \%)$ in engaged group had foetal distress and $5(13.51 \%)$ in unengaged group as compared to $2(8.69 \%)$ in engaged group had failure of induction. 
Table 3: Comparison of indications of LSCS in unengaged and engaged groups.

\begin{tabular}{|lll|}
\hline Indication of LSCS & Unengaged & Engaged \\
\hline Non-progress of labour & $18(48.64 \%)$ & $9(39.13 \%)$ \\
\hline Foetal distress & $14(37.83 \%)$ & $12(52.17 \%)$ \\
\hline Failure of induction & $5(13.51 \%)$ & $2(8.69 \%)$ \\
\hline
\end{tabular}

In unengaged group, $11(11 \%)$ patients had post-partum haemorrhage, $7(7 \%)$ patients had perineal tear, $3(3 \%)$ patients had cervical tear, $3(3 \%)$ patients had wound infection and $1(1 \%)$ patient in engaged group had postpartum psychosis whereas in engaged group, $7(7 \%), 4$ (4\%), $5(5 \%)$ and $2(2 \%)$ had same complications respectively.

Table 4: Comparison of maternal and foetal complications in unengaged and engaged group.

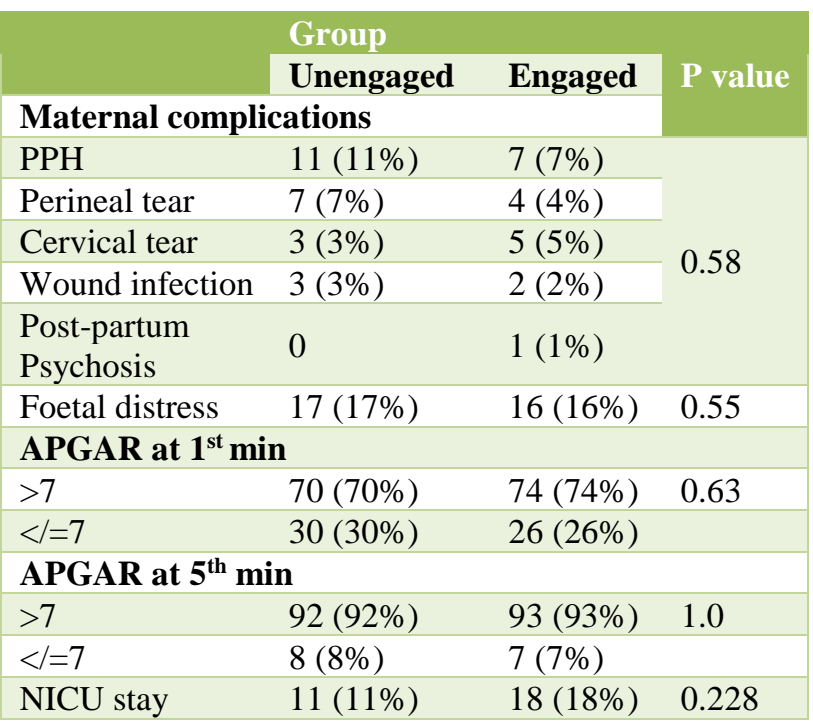

Mean birth weight in unengaged group was $2.86 \mathrm{kgs}$ as compared to $2.76 \mathrm{kgs}$ in engaged group.

\section{DISCUSSION}

Out of 100 patients in unengaged group, $71 \%$ patients presented with unengaged head at the onset of labour or at 40 weeks. In study conducted by Daniel roshanfeler et al incidence of unengaged heads was $71 \%$ as compared to $29 \%$ in engaged group which is similar to present study. ${ }^{8}$

In present study in unengaged group at onset of labour or at 40 weeks, $17(17 \%)$ were at $5 / 5,23(23 \%)$ were at $4 / 5$ and $31(31 \%)$ were at $3 / 5,28(28 \%)$ were at $2 / 5$ and $1 \%$ patient was at $1 / 5$ which was similar to Shrivastava A. in their study which had $20 \%$ free floating heads, $34 \%$ with $4 / 5$ palpable and $46 \%$ with $3 / 5$ palpable heads. Studies done by Malik et al and Shrivastav A et al showed similar results in week wise distribution of onset of labour. ${ }^{11,12}$
In present study, $73(73 \%)$ patients in unengaged group required augmentation with oxytocin as compared to 36 $(36 \%)$ in engaged group. Similar results were seen in other studies like Iqbal et al in which $72(72 \%)$ patients in unengaged group required augmentation as compared to $33(33 \%)$ patients in engaged group and Shaikh et al study had $74(74 \%)$ of patients with unengaged heads requiring augmentation of labour. ${ }^{13,14}$

In study conducted by Saima chaudhary, duration of first stage of labour was $11.04+2.04$ hours while the duration of second stage was $37.8+20.3$ mins which is similar to present study. ${ }^{15}$ In study conducted by Sudhir et al, duration of first stage of labour was $12.06+0.50$ hours while the duration of second stage was $36.3+15.2$ minutes which is similar to present study. ${ }^{16}$

Shivamurthy HM et al showed that the mean duration of active phase and the duration of second stage was shorter in engaged group as compared to unengaged group foetal. ${ }^{17}$ In present study in unengaged group, 63(63\%) were delivered vaginally (either normally or by assisted method) and 37 (37\%) were delivered through LSCS, as compared to engaged group in which $77(77 \%)$ patients delivered vaginally and $23(23 \%)$ patients delivered by LSCS.

Iqbal et al showed that incidence of LSCS was $38(38 \%)$ in unengaged group as compared to $15(15 \%)$ in engaged group which was similar to present study. ${ }^{13}$

In a study by Shivamurthy HM et al $18 \%$ of primigravida with unengaged heads had cesarean delivery compared to $6 \%$ of primigravida with engaged heads and non-progress of labour was the main reason of LSCS. ${ }^{17}$

Mahajan et al18 showed $89(59.33 \%)$ patients delivered by normal vaginal delivery, $7(4.66 \%)$ by instrumental delivery and $54(36 \%)$ delivered by LSCS and 30 $(55.56 \%)$ patients had undergone LSCS due to nonprogress of labour, $20(37.03 \%)$ due to foetal distress and $4(7.41 \%)$ due to obstructed labour and the results are similar to present study.

Similar maternal and neonatal outcome has been observed by El Nassery et al in unengaged heads. ${ }^{19}$ Maternal complications included postpartum hemorrhage in 13 patients $(8.6 \%)$, perineal and vaginal tears in 26 patients $(17.3 \%)$, Shoulder dystocia in 2 patients $(1.3 \%)$. Mean APGAR score at 1 min was $6.17+1.882(\mathrm{SD})$ and at 5 mins $8.37+1.256(\mathrm{SD})$. NICU admission was required for 8 patients $(5.3 \%)$. Mahajan et al in unengaged group showed that PPH occurred in $16(10.67 \%)$ women, perineal tear in $5(3.33 \%)$, cervical tear in $2(1.33 \%)$ while APGAR at $5 \mathrm{~min}$ was $7-10$ in $113(75.33 \%)$, 4-6 in $30(20 \%)$ and $</=3$ in $7(4.67 \%)$ neonates. $14(9.33 \%)$ neonates were admitted in NICU. ${ }^{18}$ 
Table 5: Weekwise distribution of unengaged (UE) and engaged(E) patients at onset of labour between 37-42 weeks of gestation.

\begin{tabular}{|c|c|c|c|c|c|}
\hline \multirow{2}{*}{ Gestational age in weeks } & \multicolumn{2}{|c|}{ Present study } & \multicolumn{2}{|c|}{ Malik S et al ${ }^{12}$} & \multirow{2}{*}{$\begin{array}{l}\text { Shrivastava } \mathbf{A}^{11} \\
\text { UE }\end{array}$} \\
\hline & UE & $\mathbf{E}$ & $\mathbf{U E}$ & $\mathbf{E}$ & \\
\hline $37-39$ & $41(49.38 \%)$ & $82(91.1 \%)$ & 38 & 31 & $48(48 \%)$ \\
\hline $39-40$ & $38(45.78 \%)$ & $5(5.55 \%)$ & & & $40(40 \%)$ \\
\hline $40-41$ & \multirow{2}{*}{$4(4.81 \%)$} & \multirow{2}{*}{$3(3.33 \%)$} & 51 & 60 & $10(10 \%)$ \\
\hline 42 & & & 11 & 9 & \\
\hline Total & 100 & 100 & 100 & 100 & \\
\hline
\end{tabular}

Table 6: Comparison of mean duration of labour in unengaged (UE) and engaged (E) group.

\begin{tabular}{|c|c|c|c|c|c|c|}
\hline & & $\begin{array}{l}\text { Mean } \\
\text { duration of latent } \\
\text { phase (hours) }\end{array}$ & $\begin{array}{l}\text { Mean duration } \\
\text { of active phase } \\
\text { (hours) }\end{array}$ & $\begin{array}{l}\text { Mean duration } \\
\text { of } 1^{\text {st }} \text { stage } \\
\text { (hours) }\end{array}$ & $\begin{array}{l}\text { Mean duration } \\
\text { of } 2^{\text {nd }} \text { stage } \\
\text { (mins) }\end{array}$ & $\begin{array}{l}\text { Mean total } \\
\text { duration of } \\
\text { labour (hours) }\end{array}$ \\
\hline \multirow{2}{*}{ Present study } & UE & 10.40 & 5.48 & 14.21 & 34.38 & 14.48 \\
\hline & $\mathrm{E}$ & 8.51 & 4.13 & 12.5 & 29.44 & 12.75 \\
\hline Chaudhary S et al ${ }^{15}$ & UE & & & 11.04 & 37.8 & \\
\hline Sudhir S et al ${ }^{16}$ & UE & & & 12.06 & 36.3 & \\
\hline
\end{tabular}

Table 7: Comparison of outcome of patients between unengaged and engaged groups at term not in labour and at 40 weeks or at onset of labour.

\begin{tabular}{|c|c|c|c|c|}
\hline Outcome & & Normal vaginal delivery & Instrumental delivery & LSCS \\
\hline \multirow{2}{*}{ Present study } & $\mathrm{UE}(\mathrm{n}=100)$ & $53(53 \%)$ & $10(10 \%)$ & $37(37 \%)$ \\
\hline & $E(n=100)$ & $70(70 \%)$ & $7(7 \%)$ & $23(23 \%)$ \\
\hline \multirow{2}{*}{ Iqbal et al ${ }^{13} 2009$} & $\mathrm{UE}(\mathrm{n}=100)$ & $47(47 \%)$ & $15(15 \%)$ & $38(38 \%)$ \\
\hline & $E(n=100)$ & $73(73 \%)$ & $12(12 \%)$ & $15(15 \%)$ \\
\hline \multirow{2}{*}{$\begin{array}{l}\text { Shivamurthy HM et al }{ }^{17} 2014 \\
\text { (at onset of active labour) }\end{array}$} & $\mathrm{UE}(\mathrm{n}=100)$ & $68(68 \%)$ & $14(14 \%)$ & $18(18 \%)$ \\
\hline & $E(n=100)$ & $88(88 \%)$ & $6(6 \%)$ & $6(6 \%)$ \\
\hline
\end{tabular}

Shaikh et al in unengaged head showed that, PPH occurred in $10 \%$ women, perineal tear in $2 \%$, wound infection in 7\% while APGAR at 5 min was $7-10$ in $75 \%$, 4-6 in $20 \%$ and $</=3$ in $5 \%$ neonates. 10 neonates were admitted in NICU. ${ }^{14}$

Mean birth weight in unengaged group was $2.8 \mathrm{~kg}$ and in engaged group it was $2.7 \mathrm{~kg}$ in present study.

In study done by Dayal $\mathrm{S}$ et al where they studied primigravidas with engaged and unengaged fetal head, they observed that the mean birth weight was $2.77 \mathrm{~kg}$ in the unengaged group and $2.065 \mathrm{~kg}$ in engaged group. ${ }^{20}$ The difference in birth weight in 2 groups was statistically significant which is very similar to present study

\section{CONCLUSION}

In primigravida, engagement of foetal head is delayed either during term or during labour and this unengagement causes anxiety in the minds of obstetrician due to prolonged duration of labour and higher incidence of medical and surgical intervention and a risk factor for
LSCS. If the attitude of watchful expectancy and timely intervention is used in these cases, especially in cases where no aetiological factor is found for unengaged head, by plotting partogram and using oxytocin judiciously when labour appears to be taking a protracted course, most of these patients will deliver vaginally with minimal maternal and foetal morbidity and will avoid hasty decisions towards caesarean section.

Funding: No funding sources

Conflict of interest: None declared

Ethical approval: The study was approved by the Institutional Ethics Committee

\section{REFERENCES}

1. Cunningham FG, Leveno KJ, Bloom SL, Hauth JC, Gilsirap LC III, Wenstroom KD. Williams Obstetrics. 22nd ed. Stanford, USA: Appleton and Lange; 1997. pp. 153-60,415-24,496-501.

2. Charles G Slipp. The primigravida in labour with high fetal station. Am J Obstet Gynecol. 1969;104(2):267-72. 
3. Qureshi NS, Saleem F, Riaz S. Primigravida with non-engaged foetal head at term: an audit of delivery outcome. Ann King Edward Med Coll 1999;5(2):177-9.

4. Murphy K, Shah L, Cohen WR. Labour and delivery in nulliparous women who present with an unengaged foetal head. J Perinatol. 1998;18(2):1225.

5. Friedman EA and Sachtleben MR.Station of fetal presenting, part-II, Effect on course of labour. Am J Obstet Gynecol 1965;93(4):530-55.

6. Thenmozhi RV. And Iyer L. Effect of engagement of head on labour. J Obstet Gynacol India. 1984;35(6): 1060-6.

7. Altman MR, Lydon-Rochelle MT. Prolonged second stage of labor and risk of adverse maternal and perinatal outcomes: a systematic review. Birth. 2006;33(4):315-22.

8. Daniel Roshanfeler, Karen J Blakenore, Judy LEE. Nancy A. Hueppcheu, Frank R. Witter. Station at onset of active labor in nulliparous patients and risk of cesarean delivery. Obstet and Gynecol 1999;93(3):329.

9. Chougtu L, Khanum W.. "Labour in primigravidae with unengaged heads". J Obstet Gynacol India. 1977;27(4):329-32.

10. Lakshmidevi M, Malini KV, Shetty VH. Partographic analysis of spontaneous labour at term in primigravida. $\mathrm{J}$ Obstet Gynecol India. 2012;62(6):635-40.

11. Srivastava A. Obstetrical Outcome in Primigravida with Unengaged Fetal Head at Spontaneous Onset of Labour at Term Geastation. 2017;6(5):2618-23.

12. Malik S, Asif U, Asif M. Obstetical outcome of primigravida; engaged versus unengaged foetal head with spontaneous onset of labour at term. Professional Med J. 2016;23(2):171-5.
13. Iqbal S, Sumaira S. Outcome of primigravida with unengaged versus engaged fetal head at term or onset of labour. Biomedica. 2009;25:159-62 .

14. Shaikh F, Shaikh N, Shaikh N. Outcome of primigravida with high head at term. J Pak Med Assoc. 2014;64(9):1012-4.

15. Chaudhary S, Farrukh R, Dar A, Humayun S. Outcome of labour in nullipara at term with unengaged head. J Ayub Med Coll Abbottabad 2009;21(3):131-134.

16. Sunita S, Mishra S, The outcome of labour in primigravida with term gestation and unengaged head at onset of labour. Indian J Obstet Gynecol Res. 2016;3(3):199-20

17. Shivamurthy HM, Asaranna D, Giridhar SA, Jannu P, Jassawalla N, Himgire JR. Comparative study of labor course in primigravida with unengaged head in active labour, with those having engaged head. Medica Innovatica. 2014;3(2):84-9.

18. Mahajan N, Tabassum S, Fareed P. Outcome of high fetal station in Primi-Gravida at term in labour. Int $\mathbf{J}$ Reproduct, Contracep, Obstet Gynecol. 2017;5(3):873-7.

19. EL Nassery NS, EL Kattan EA, Fouad MA. Unengaged Head in Primigravidas, Will it Affect the Chance of Having a Vaginal Birth? Medical J Cairo University. 2013;81(2).

20. Dayal S, Dayal A. Outcome of Labour in Nullipara at term with unengaged vertex. Int J Medical Res Review. 2014;2(2):17-23.

Cite this article as: Bhadra DM, Sonawane PK. Comparative study between unengaged and engaged fetal head in primigravida at term or in labour. Int $\mathbf{J}$ Reprod Contracept Obstet Gynecol 2018;7:4569-74. 